\title{
Simulation and Optimization of Isopropyl Lactate Manufacturing Process
}

\author{
OLGA VALERICA TAGA (SAPUNARU) ${ }^{1}$, CLAUDIA IRINA KONCSAG ${ }^{2 *}$, COSMIN J INESCU $^{1}$, ALINA MONICA MARES ${ }^{1}$ \\ 'University Politehnica of Bucharest, Faculty of Applied Chemistry and Materials Science, 1-7 Gh. Polizu Str., 011061, Bucharest, \\ Romania \\ University Ovidius of Constanta, Faculty of Applied Science and Engineering, 124 Mamaia Blvd., 900527, Constanta, Romania
}

\begin{abstract}
The new chemical processes are investigated in laboratory, usually in batch, with pure reactants, and specific laboratory methods applied for the purification of the products. Scaling-up processes means passing from batch to continuous process, using feed with impurificators, industrial equipment for separation and recirculation or purge for an economic operation with special care for safety and environment. This is why, following a study in laboratory for isopropyl lactate obtaining by transesterification in reactive distillation system, a flowsheet of the industrial process was proposed in this paper. Simulations of the transesterification process were performed. The purpose of these simulations has been to find the optimum solution from energy consumption point of view. Optimum parameters of the reactive distillation were found: the molar ratio isopropanol/methyl lactate $R=1.06$, the number of theoretical stages in the distillation zone NTS=2.4 and the reflux ratio $R R=2$, in a process that produces $1.3 \mathrm{t} / \mathrm{h}$ IPL of $96 \%$ wt purity.
\end{abstract}

Keywords: reactive distillation, transesterification, isopropyl lactate, process simulation

The reactive distillation process (RD) can be implemented by integration of two operation units (reaction and distillation) in a single column. This arrangement is feasible for reactions limited by thermodynamic equilibrium and when the favorable conditions for reaction (temperature, pressure) can be found somewhere in the column.

There are numerous studies concerning the modelling and simulation of RD. Taylor and Krishna [1] reviewed these works and noted that older w orks consider a column with a certain number of stages processing a multicomponent system. This is mathematically represented by a system of linearized equations proceeding from material and energy balance. There are rigorous methods for solving this system and find an exact solution [2-4]. The solution consists in the profile of concentrations in the column.

The commercial software includes models based on chemical equilibrium or kinetics. The success of the simulation depends on the choice of a certain model. The thermodynamic approach seems more facile but choosing the most appropriate thermodynamic model ensures the success.

There are models the simulations for the esterification processes in literature [5-7]. As for reactive distillation applied in transesterification, Wang et al. proposed a flow sheet for the methyl acetate transesterification reaction with n-butanol in n-butyl acetate synthesis [8] consisting of a reactive distillation column (column $\mathrm{RD}$ ) and a recycle distillation column (column RC) wherein the formed azeotropes can be easily separated and recirculated. This could constitute the model for a flow sheet in manufacturing of the isopropyl lactate, due to similarities between reactions and physical properties of substances.

Based on the literature studies and own previous results of experimental studies $[9,10]$, a process flowsheet was set-up, and the process parameters were optimized by simulations in CHEMCAD, in this work.
Simulations of the transesterification process for isopropyl lactate manufacturing

Since the experiment took place within relatively narrow limits imposed by the experimental facilities, the simulation in ChemCad aimed to find the optimum parameters in industrial context.

Contributions to optimization of processes were performed by other authors [11-13] for a process in steady state, or in a dynamic process [14], in a similar simulation medium (Aspen, HySys).

The objectives of simulations were to find an energetically efficient process, with a good recovery degree and high purity of the main product.

\section{Experimental part}

Based on previous experimental data [9], a flowsheet was proposed for industrial process that is shown in the Figure 1.

The process is relatively simple. For simulation purposes, the reactive distillation is composed from a reactor (1) and a distillation column (3) having only a rectification section, due to the fact that the reactor effluent feeds the column on the lower plate. The Reactive Distillation Sequence works at 1.2 bar abs. The reactor (1), fed with $10 \mathrm{kmol} / \mathrm{h} \mathrm{ML}$ and a molar flow of IPA adjusted to correspond to different molar ratios, also taking into account the IPA and $M L$ recycle. The reactor is a stoichiometric type needing no kinetics knowledge, but conversion. The conversion can be calculated at different molar ratios of reactants, from the experimental study or by estimation with the mathematical model (Eq.1) found in [9]:

$$
y=8.727+7.330 x_{1}+18.419 x_{2}+1.084 x_{3}
$$

The distillation zone (3) has the same temperature in bottom as the effluent $\left(120^{\circ} \mathrm{C}\right)$; the temperature and the composition of vapours at the top depend on the number

*email: ckoncsag@yahoo.com 


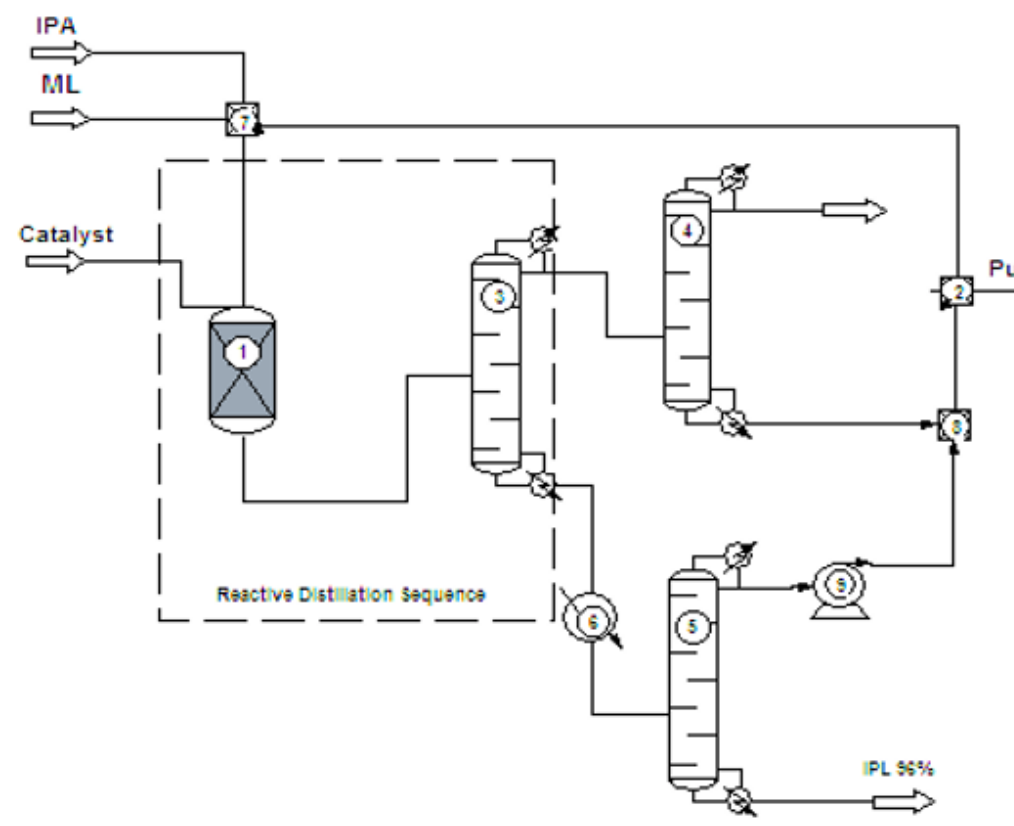

of stages and the reflux ratio, and these factors are to be investigated in this study. The methanol and isopropanol are split at 1.2 bar in a column (4), where the distillate is a by- product (methanol) and the bottom product is isopropanol recycled to the reactor. The product purification is performed in a column (5) working at 0.1 bar, where the isopropyl lactate is obtained at the bottom. The distillate of column (5) contains mainly methyl lactate and isopropanol, so it is recycled to the reactor. A purge of $5 \%$ from the recycling flow is provided to avoid accumulation of undesirable compounds (methanol, isopropyl lactate) in recycle. The flowsheet for simulations doesn't include all the minor equipment (influencing in equal measure any variant of RD), such as a unit for drying the feed or a separator for the catalyst.

\section{Results and discussions}

In the simulation process the main three factors affecting the reactive distillation are investigated: the reactants molar ratio, the number of stages and reflux ratio, but the simulation of the entire process is also necessary to draw conclusions.

In first instance the number of stages in the distillation zone of RD was simulated between 4 and 16 , considering a molar ratio of reactants $R=4$. Taking into account that these are real stages (plates) and the efficiency of a real plate is around 0.4 for foaming systems, they correspond to 1.6-6.4 NTS. It was searched the influence of this number on the reboiler /condenser duty and the concentration of IPL in the distillate as an expression of the IPL recovery in the bottom. Results are presented in Figure 2.

From Figure 2, one can observe a sensitive decrease of reboiler duty (from $267655 \mathrm{kcal} / \mathrm{h}$ to $258491 \mathrm{kcal} / \mathrm{h}$ ), of condenser duty (from $734121 \mathrm{kcal} / \mathrm{h}$ to $724211 \mathrm{kcal} / \mathrm{h}$ ) and also of the IPL concentration in distillate (from $0.63 \%$ wt to $0.03 \% \mathrm{wt}$ ) when increasing the number of stages from 4 to 6; over 6 , all these parameters decrease very few; this is why, the optimum number of stages was considered 6 (corresponding to NTS=2.4).

The reflux ratio in the reactive distillation was simulated between $R R=0.5$ and 6 . The effect of RR on the methanol and IPA recovery in distillate is shown in Figure 3. The recovery degree for methanol in distillate increases from $97.7 \%$ at $R R=0.5$ to $98.9 \%$ at $R R=2$, then it increases slowly to $99.3 \%$ at $R R=6$. The recovery degree for IPA in distillate decreases from $93.8 \%$ at $R R=0.5$ to $93.2 \%$ at $R R=2$, then

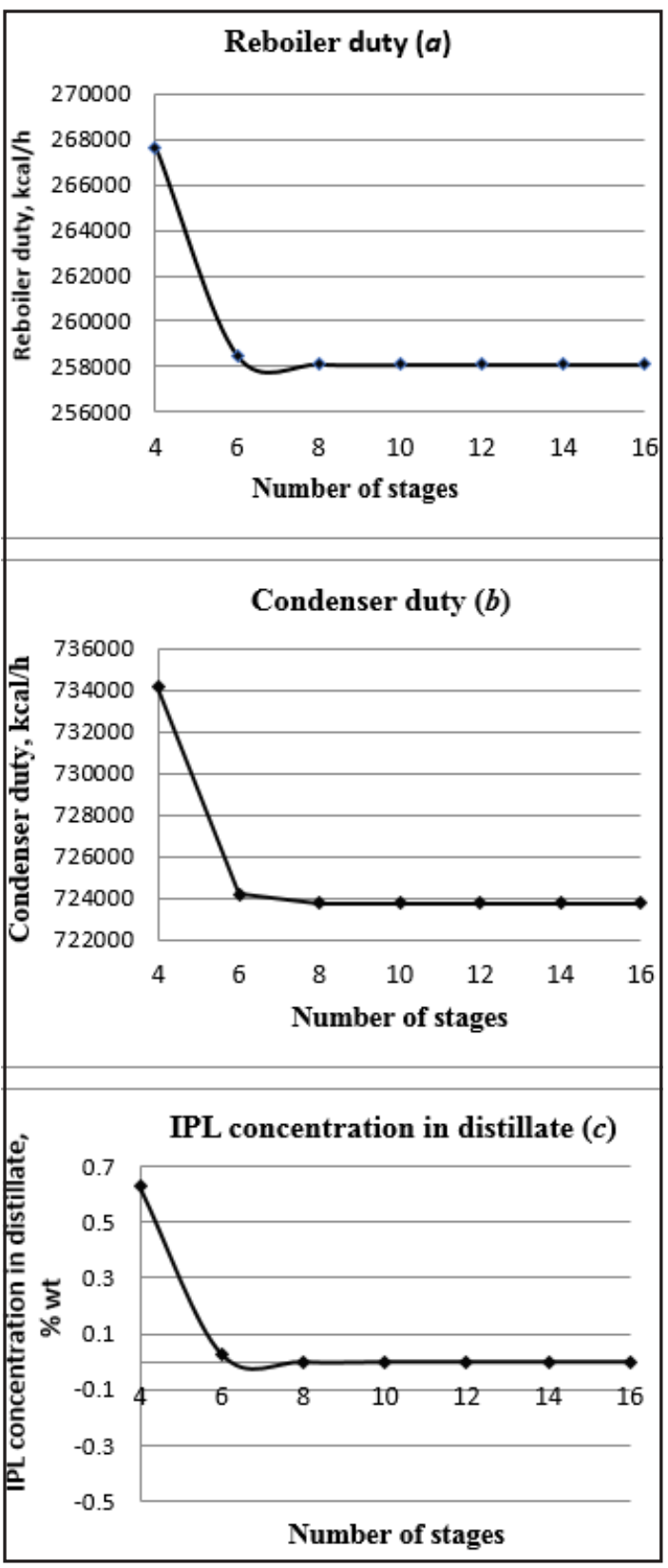

Fig. 2. Influence of number of stages in the RD column on the reboiler ( $a$ ) and condenser duties (b), and on the IPL concentration in distillate $(c)$

slowly decreases to $92.9 \%$ at $R R=6$. Following these observation, the optimum RR was established at 2 .

With optimum parameters established in the distillation zone of RD (number of stages 6 and reflux ratio 2) the simulations on the process flowsheet were performed for reactants molar ratio at (1.06:1); (2:1); (3:1) and (4:1) 


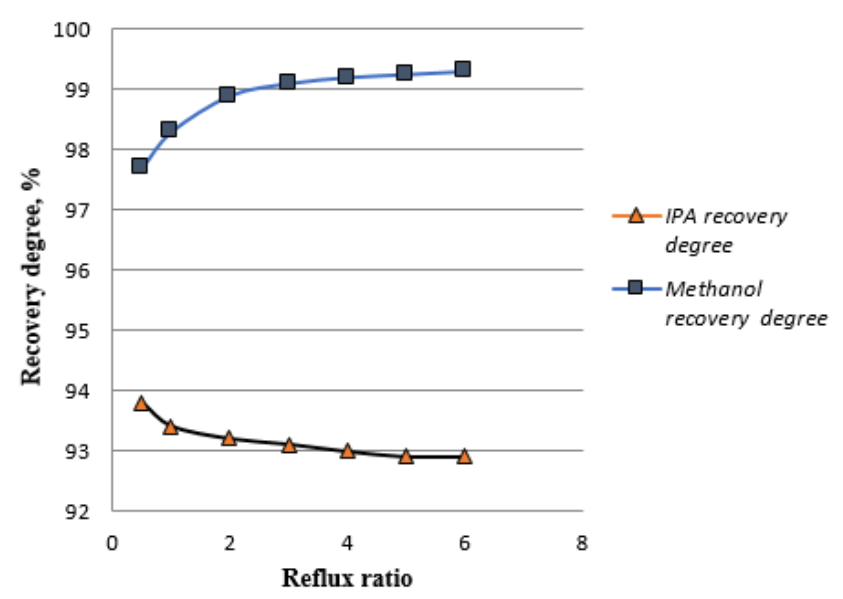

Fig. 3. Influence of reflux ratio in the RD column on the separation of IPA and methanol from the reaction mass

Table 1

RESULTS OF PROCESS SIMULATION FOR MANUFACTURING $1.3 \mathrm{t} / \mathrm{h}$ ISOPROPYL LACTATE

\begin{tabular}{|c|c|c|c|c|c|}
\hline $\begin{array}{c}\text { Molar ratio } \\
\text { ML:IPA }\end{array}$ & $\begin{array}{c}\text { Heating duty per } \\
\text { ton IPL, kcalt }\end{array}$ & $\begin{array}{c}\text { Cooling duty per } \\
\text { ton IPL, kcalt }\end{array}$ & $\begin{array}{c}\text { IPL purity, } \\
\% w t\end{array}$ & $\begin{array}{c}\text { IPL recovery } \\
\text { degree, } \\
\% w t .\end{array}$ & $\begin{array}{c}\text { Methanol } \\
\text { byproduct purity, } \\
\% w t .\end{array}$ \\
\hline $1.06: 1$ & $1.26 \times 10^{\circ}$ & $1.26 \times 10^{\circ}$ & 96.0 & 99.998 & 97.8 \\
\hline $2: 1$ & $1.34 \times 10^{\circ}$ & $1.34 \times 10^{\circ}$ & 96.0 & 99.994 & 92.5 \\
\hline $3: 1$ & $1.45 \times 10^{\circ}$ & $1.45 \times 10^{\circ}$ & 96.0 & 99.997 & 96.9 \\
\hline 4.1 & $1.36 \times 10^{\circ}$ & $1.36 \times 10^{\circ}$ & 96.0 & 99.998 & 97.0 \\
\hline
\end{tabular}

IPA/ML. The molar ratio had to be over 1:1, for maintaining a recycle flow.

The simulations of the entire process were performed after establishing the parameters of the columns (4) and (5). The column (4) - splitting the methanol / isopropanol mixture- works at 1.2 bar, contains 20 stages fed on the $10^{\text {th }}$ stage, and has a reflux ratio of 8 , to ensure the purity of the by-product methanol. The IPL purification column (5) working at 0.1 bar, has also 20 stages fed on the $15^{\text {th }}$ stage (counted from up down) with 3 reflux ratio, to ensure the IPL purity.

The main objective of the simulation is the minimum specific energy consumption ( $\mathrm{kcal} / \mathrm{t}$ IPL) for ensuring a purity of $96 \%$ for IPL and a high recovery degree from the reaction mass. Also, the purity of the methanol-by-product is important for commercial purposes.

The heating and the cooling duties of the entire process were found in the energy balance report and they are approximately equal. The heating and cooling utilities are needed mainly at the reboilers and condensers.

The results of the simulations are presented in Table 1.

Since the IPL purity and the recovery degree were approximately the same in all cases, the methanol purity was between $92.5 \%-97.8 \%$ wt., due to the effluent composition.

There is a variation in energy consumption per ton IPL, also due to the effluent composition and the feed flowrate in columns (3), (4) and (5).

From Table 1, it results that w orking at small molar ratio of reactants (1.06:1) ensures the lowest specific energy consumption per ton of isopropyl lactate.

\section{Conclusions}

This work was dedicated to the simulation in CHEMCAD of the transesterification process to obtain isopropyl lactate by reactive distillation.

In previous experimental study the influence of main factors on the process performance has been established and a mathematical model was performed for the prediction of the methyl lactate conversion as a function of these factors' values.

Following the previous experimental study [9], the flowsheet of an industrial process was proposed and

simulations in CHEMCAD were performed for the optimization of the reactive distillation sequence, having as an objective the minimization of the specific energy consumption per ton of IPL produced. For a production of $1.3 \mathrm{t} / \mathrm{h}$ IPL with purity of $96 \%$, the lowest energy consumption was reached at the molar ratio IPA:ML of 1.06:1, in a reactive distillation column with 6 plates (equivalent to 2.4 theoretical stages) and at a reflux ratio of 2 .

In conclusion, the manufacture of isopropyl lactate by the transesterification of methyl lactate with isopropanol in acid catalysis is feasible both technically and economically and the flow sheet proposed here can be considered for the IPL industrial process.

\section{References}

1.TAYLOR, R., KRISHNA, R., Chem. Eng. Sci., 55, 2000, p. 5183

2. SUZUKI, I., YAGI, H., KOMATSU, H., HIRATA, M., J. Chem.Eng.J pn., 4, 1971, p.26;

3.HOLLAND, C.D., Multicomponent distillation, Prentice Hall, New York, 1963

4.KOMATSU, H., HOLLAND, C.D, J. Chem. Eng. J pn., 10, 1977, p. 292

5.PEREZ-CISNEROS, E., SCHENK, M., GANI, R., PILAVACHI, P.A., Comput. Chem. Eng., 20, 1996, p. 267

6.PILAVACHI, P.A., SCHENK, M., PEREZ-CISNEROS, E., GANI, R., Ind. Eng. Chem. Res., 36, 1997, p.3188

7.KREUL, L.U., GORAK, A., DITTRICH, C., BARTON, P.I., Comput Chem Eng, 22, 1998, p.371

8.WANG, S.J., HUANG, H.P., YU, C.C., Ind. Eng. Chem. Res., 50, 2010, p.1321

9.TAGA, O.V., KONCSAG, C.I., SIVRIU, A.M., JINESCU, G., Rev. Chim. (Bucharest), 70, no 1, 2019, p. 18

10.TAGA, O.V., KONCSAG, C.I., MARES, A.M., JINESCU, G., Rev. Chim. (Bucharest), 69, no 12, 2018, p. 3423

11.BILDEA, C.S., VOS, F.S., Rev. Chim. (Bucharest), 56, no. 11, 2005, p.1106

12.DRAGNEA, P., BILDEA, C.S., Rev. Chim. (Bucharest), 67, no. 9, 2016, p.1813

13.NICOLAE, M., Rev. Chim. (Bucharest), 68, no. 1, 2017, p.28

14.DRAGNEA, P., BILDEA, C.S., Rev. Chim. (Bucharest), 68, no. 5, 2017, p.982.

Manuscript received: 20.11 .2018 